\title{
Challenges for Industrial Robot Applications in Food Manufacturing
}

\author{
Farah Bader \\ Centre for SMART, Wolfson Engineering School at \\ Loughborough University, Ashby Road \\ Loughborough, LE11 3TU, UK \\ f.n.k.bader@lboro.ac.uk
}

\author{
Shahin Rahimifard \\ Centre for SMART, Wolfson Engineering School at \\ Loughborough University, Ashby Road \\ Loughborough, LE11 3TU, UK \\ s.rahimifard@lboro.ac.uk
}

\begin{abstract}
The global food industry is facing many challenges due to the impact of climate change, ever-changing demands by consumers, and increasing legislative pressures by the government, which have resulted in several drivers for changes. Current large-scale rigid manufacturing systems are increasingly seen as incapable of supporting the underlining requirements for implementation of such changes. In this context, one of the key requirements is the need for improved flexibility and reconfigurability of production facilities, often provided by adoption of Industrial Robots in other manufacturing sectors. However, despite their recent technological advancements, in particular the advent of the 4 th industrial revolution (Industry 4.0), and significant reduction in overall implementation cost over the last two decades, the uptake of industrial robots in food processing has been slow. This paper explores the application of industrial robots in food manufacturing, the benefits of their use and the challenges currently hindering their uptake.
\end{abstract}

\section{CCS Concepts}

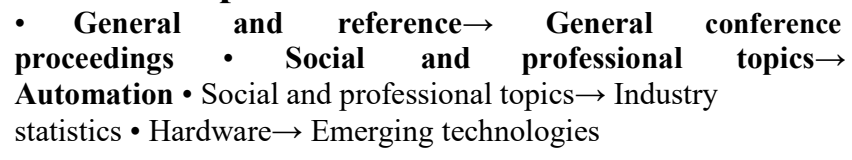

\section{Keywords}

Industrial Robots; Food Manufacturing; Flexible Automation.

\section{INTRODUCTION}

The global food industry is one of the biggest manufacturing sectors. In the UK, it employs 3.9 million people across 11,000 manufacturing sites, and contributes more than $£ 28$ billion to the economy [3,11]. The small and medium enterprises (SMEs) make up over $90 \%$ of the UK food manufacturers [49], and modern challenges in the food production have threatened to surpass SMEs who generally have limited capability to change and adapt. Depleting natural resources, climate change effects on agriculture, every-increasing legislations and regulations posed by governmental bodies, and the decreased availability of labour are changing the way the food industry operates. Further demands by consumers as a result of globalisation, growing and aging

Permission to make digital or hard copies of all or part of this work for personal or classroom use is granted without fee provided that copies are not made or distributed for profit or commercial advantage and that copies bear this notice and the full citation on the first page. To copy otherwise, or republish, to post on servers or to redistribute to lists, requires prior specific permission and/or a fee.

ISCSIC '18, September 21-23, 2018, Stockholm, Sweden $\mathbb{C}$

2018 Copyright is held by the owner/author(s).

ACM ISBN 978-1-4503-6628-1/18/09.

https://doi.org/10.1145/3284557.3284723 population, dietary needs and trends are also contributing to a shift in methods of food product development and manufacturing. All of these modern changes pose concerns on organisations within the food industry as they try to maintain their production and consumer satisfaction.

As seen in other industries, responding to such challenges requires the adoption of higher-level technologies, predominantly; automation via industrial robots (IR). Thus far, the automotive industry has been one of the biggest benefactors of robotic automation. IR uptake by the automotive industry increased $12 \%$ per year between 2011 and 2016. They are employed in repetitive tasks such as cutting, stamping, welding and assembly, as well as end of line processes; spray painting and coating. Similarly, the electrical and electronics industry has adopted IR for cutting and assembly of parts and products such as computers, TVs and other precision electronic equipment. Sale of IR to the electrical and electronics market grew 19\% per year between 2011 and 2016 as a result of the increased demand for innovative electronic products [4]. For these industries, and many more, IR allowed for the improved flexibility and reconfigurability required for product variability. With the use of IR, organisations were able to keep up with consumer demands and product innovation, therefore increasing their market shares and maintaining consumer satisfaction. Such benefits are also reported by all other manufacturing industries that adopt IR automation.

Recent studies have identified the food industry as one of the utmost potential benefactor from IR automation [9,21], highlighting an urgent need for an investigation into the use of IR and their benefits to food manufacturing. This paper begins by exploring the current challenges affecting the global food industry. The initial sections of the paper provide a brief overview of the industrial revolutions' effects on the food sector throughout the years and specific drivers for wider uptake of IR in food production. The later sections highlight the challenges hindering the adoption of IR and outline the future projections for higher uptake despite these obstacles.

\section{THE INDUSTRIAL REVOLUTIONS FROM A FOOD MANUFACTURING VIEWPOINT}

Caldwell [5] defines food factories as "an amplified version of domestic procedures of manual food preparation'". Current automated food processing was developed as a response to increasing demand, however, the majority of these processes still heavily rely on human employees due to the required flexibility and dexterity [13]. Modern processed food products were introduced in early 20 th century after the industrial revolutions facilitated the development of technology and manufacturing 
operations. During the first industrial revolution, steam and water power were utilized for mechanical production, aiding with large scale production of staple ingredients such as sugar and flour. The second industrial revolution introduced electrical energy, which allowed for the construction of specialised machinery for food processing. This allowed automated food production and assembly lines to be created for mass production of a limited range of products. During this period, advanced technologies were emerging, allowing for canned and pasteurized foods with longer shelf lives to be commercialized. The third industrial revolution introduced electronics and computer integrated manufacturing, which enabled faster more efficient utilisation of several pieces of machinery, permitting mass production of composite food products such as ready-to-eat meals and energy dense foods fortified with vitamins and minerals $[15,35]$.

The fourth industrial revolution; Industry 4.0, delivers the use of the Internet of Things (IoT) for a more cyber-physical manufacturing system. Industry 4.0 aims to promote the use of artificial intelligence and robots in every sector. It promises automation and control of all operations on a single platform, enabling consistent monitoring and traceability $[35,43]$. In order to prepare and accommodate Industry 4.0, manufacturers are encouraged to become more technologically advanced. This includes adopting sophisticated control systems and advanced software unified with highly advanced sensory devices [46]. In this context, Industry 4.0 will enable food industry to develop better traceability and trackability of their ingredients, processes and products and to improve food safety and quality. Furthermore, the use of sensors and detection technologies facilitates better food labelling and handling and minimising food waste [50]. Figure 1 outlines the relationship between Industry 4.0's capabilities and their relation to the food supply chain's current challenges. For successful transition into Industry 4.0, food manufacturers first require the adoption of a higher level of automation, which also include IR automation [39].

\section{FLEXIBLE AUTOMATION THROUGH IR IN FOOD MANUFACTURING}

According to the International Organization for Standardization, an industrial robot is "An automatically controlled, reprogrammable, multipurpose manipulator programmable in three or more axes, which can be either fixed in place or mobile for use in industrial automation" [27]. IR are primarily composed of three parts, the base, the arm and the wrist, with joints connecting them together to form a unit. At the end of the wrist, an end-effector is added, this can be either a gripper for grasping and moving of object, or a tool, for physical manipulation of an object. The variety of the IR, in terms of physical configuration, size and type of end-effector is dependent on the application requirements. Both automated machines and IR can work independently of human supervision, however,

IRs possess the high technology level that supports flexibility and reconfigurability characteristics required to respond to their environments $[18,26]$. IRs offer the ability to operate a variety of systems under many processes to produce any product in desired amounts. They can also be reconfigured in real time to deal with new process or material $[10,18]$. Given these wider range of benefits, the uptake of IR in food sector has been slow due to a number of specific limitations and doubts. Many companies believe their procurement can be costly and timeconsuming, while others think their processes are too complicated. Such reservation exists more within SME food manufacturers which highlights a drastic change in their approach towards adoption of IRs within their production facilities [16-17].

\section{DRIVERS FOR IRS IN FOOD MANUFACTURING}

The global food industry is facing many pressures for change in current operations. The following section explores four main stakeholders in the UK driving for operational changes in food manufacturing; the consumers, the government, the workforce and the manufacturers.

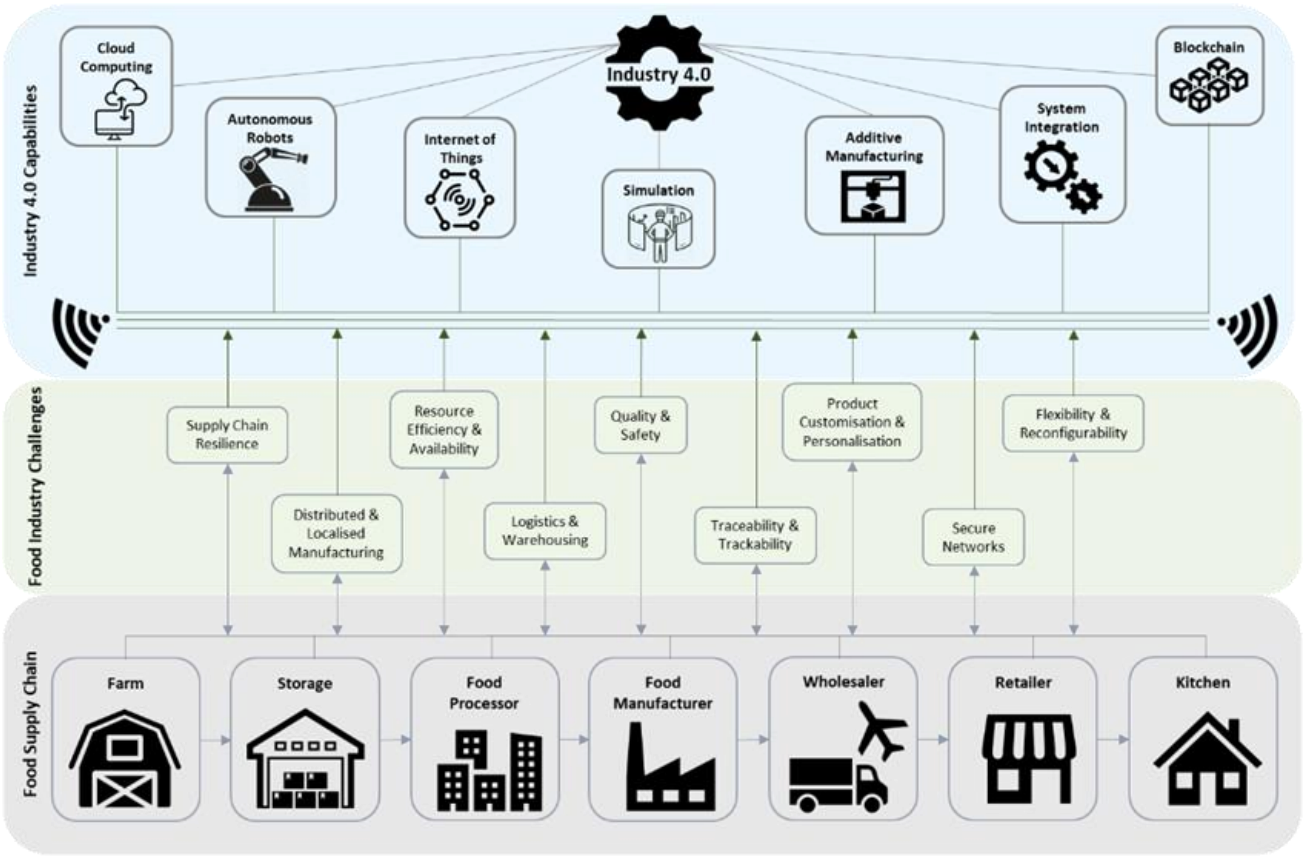

Figure 1. The relationship between Industry 4.0 capabilities and the food supply chain in tackling the challenges posed on the food industry. 


\subsection{Consumer}

By 2030 , there will be approximately 71.3 million people residing in the UK, 15.5 million of which will be over $65 \mathrm{yr}$ old who will require personalised, reformulated foods [34]. Reformulated food processing requires a high level of flexible automation, in particular the elderly will require specialised foods that are suitable for their mastication and digestion abilities [15]. On the other hand, millennial consumers are demanding more convenient foods, such as preserved foods, pre-prepared and instant meals. The ready meal and food-to-go market is expected to grow $35 \%$ by 2021 [20-21]. The population growth will also bring along multiple novel ingredients from a variety of ethnicities, pressuring the industry to produce innovative foods with these ingredients and more cultural diversity. Furthermore, the recent revolution of health awareness and allergen mindfulness has made consumers demand foods with better nutritious quality. Currently 1 in 5 UK citizens consider themselves to have a food allergy or intolerance, $12 \%$ of which follow a vegan diet, $39 \%$ are dairy free and $35 \%$ are gluten free. $[5,22]$. Globalisation and connectivity has resulted in the widespread of trends, especially in super-food ingredients. Foodstuffs with unique nutritional properties are considered superfoods. These ingredients are thought to possess extra nutritional benefits to the consumer from properties such as antioxidants and multiple vitamins or minerals. Goji berries, kale and quinoa are just some examples of ingredients labelled as super-foods which swept over markets as their trends emerged. [57]. Such demands open the market for customised and personalised foods, both of which require operational changes in manufacturing. Customised products are aimed at consumers with specific preferences who make food decisions based on likes and dislikes. Whereas personalised foods are for consumers with restricted choices with dietary requirements. Successful exploitation of these market opportunities is highly dependent on the speed at which production facilities can respond to the product changes. [2,23].

\subsection{Government}

Governmental bodies are increasing pressures on food manufacturers to improve their compliance to policies and legislations. They are encouraging better employees' safety in manufacturing environments, where $15 \%$ of the UK's total manufacturing injuries are reported by the food industry. Manual handling related injuries such as tendinitis and lower back discs have caused a loss of 0.9 million productive working days annually in the UK [22]. Annually, 80 broken limbs and skull fracture injuries are caused by falls from ladders and raised platforms [23]. Food safety is also a major issue as regulators encourage manufacturers to eliminate all sources of food contamination in hopes of preventing the on-spread of diseases. This highlights the need for better traceability and trackability of foodstuffs and their journey through production, to the point of consumption. [26-27]. Furthermore, it was found that the manual operations in the food industry can be highly contaminated due to failure to wash and sanitization [13]. New procedures are also motivating producers to provide better labelling for consumers to fully understand the content of their food products [12]. Industry leaders are encouraging producers to be more socially aware, and to take into account public health, especially in combating diabetes and obesity, two of the largest health issues in the UK

[15]. Sustainability is also a major topic, with energy and food waste being the top two concerns. The UK's food sector consumes approximately $12 \%$ of the total industrial energy usage, making it responsible for 11 million tonnes of $\mathrm{CO}_{2}$ annually [5]. Approximately 10 million tonnes of food waste are generated annually, with 1.7 million tonnes attributed to food manufacturing processes alone, $51 \%$ of which is avoidable. Majority of this is considered by-products or rejected products which can be avoided with better automation and monitoring systems [1,29].

\subsection{Workforce}

Brexit has resulted in increased concerns among EU employees in the UK's food industry, with $31 \%$ of food enterprises have already seen EU employees leave [47]. This has evidently become a huge challenge, with $57 \%$ of food manufacturers already struggling to find labour and skilled employees for their business needs [4]. Moreover, readily available employees are becoming highly expensive, with a steady increase in labour costs seen over the past decade [40]. While human labourers are highly important and essential in the UK food industry, the increasing workforce demands and pressures have highlighted the need for an urgent need to consider various automation capabilities and technologies within food processing [40].

\subsection{Manufacturer}

Every manufacturer has a continuous goal to improve their operations and increase their market competitiveness. Many businesses believe that to meet these goals they must respond to all consumer demands. In doing so, they hope to increase productivity, efficiency and quality as well as reduce costs and wastes. They also strive to abide by legislations and limit hazards emissions to protect their employees and consumers. However, with the other above-mentioned challenges, meeting these goals is becoming increasingly difficult. [4]. A survey by Campden BRI.

[7] found that $63 \%$ of food manufacturers intend to use innovation to increase their product and market competitiveness. A major concern for these manufacturers was that their limited time and resources hinders their ability to invest in innovation [34].

\section{IR APPLICATIONS IN FOOD MANUFACTURING}

Characteristically, there are three common motives for using IR in food processing. The first is their efficient performance, which allows for repeatability, accuracy and high-speed production of well-defined processes. The second is their durability, IR can perform tedious, undesirable jobs in a variety of harmful and adverse environments. Finally, IR are highly flexible, therefore they can adapt and reconfigure to provide a variety of products under an assortment of processes. These characteristics make IR ideal for applications in food processing, especially in the following four scenarios:

A. Bottleneck situations; often occur in a production line where a single process causes production to slow down or stop completely, thus decreasing productivity and frustrating employees. Some bottlenecks may cause delays and pile-ups throughout the processing line, resulting in damaged products. Bottlenecks are commonly caused by rigid automated processing equipment, for example the pie filling process requires human operators to maintain high speeds and continuous operations without the opportunity to slow down to react to unplanned events or to have a break. Introducing flexible automation in the form of IR into bottleneck processes will ensure flexibility required to work within operator's capability while maintaining the speed needed for high productivity. For customised and personalised marshmallow producer, Boomf, the simple task of cutting marshmallow squared previously took human workers 5 minutes and caused a bottleneck in the production line. After employing an IR, this task was completed in 17 seconds, increasing efficiency by $600 \%$. [43]. 

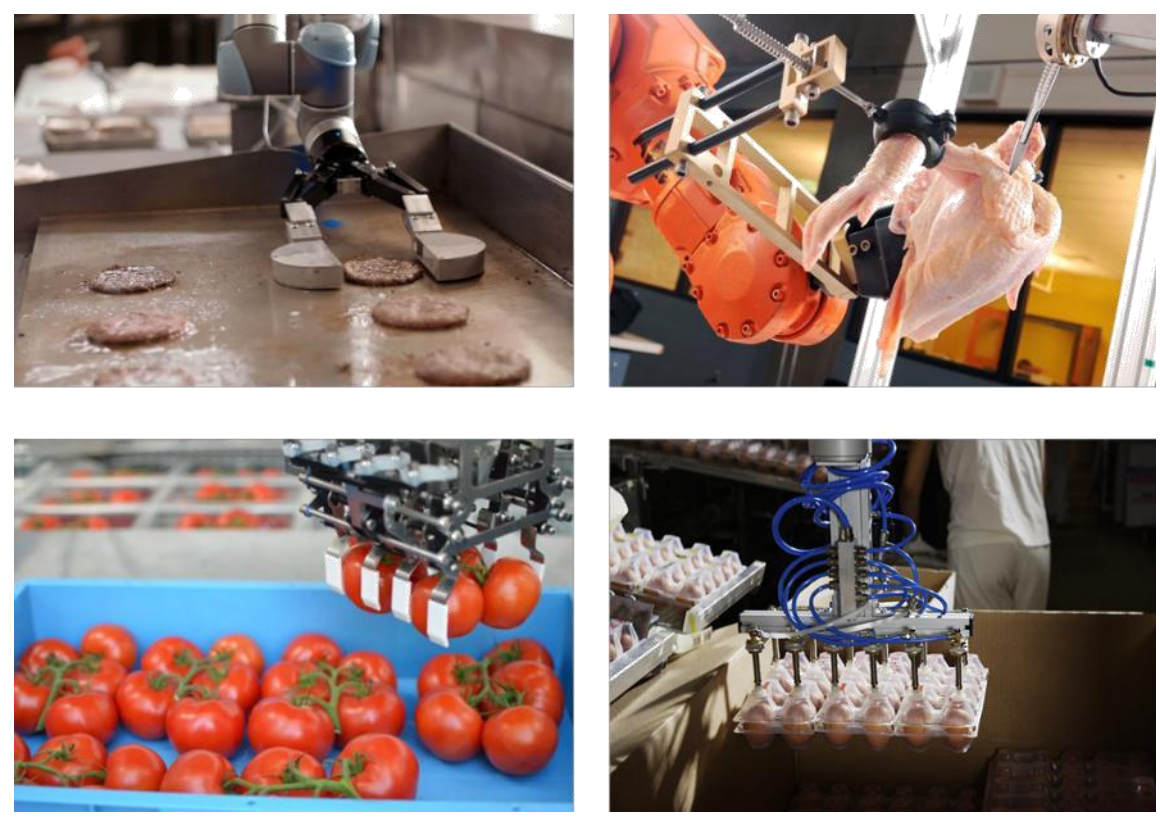

Figure 2. IR applications in the food industry (a) Assembly operation as IR lifts a cooked beef patty and transfers it to a burger bun, (b) Processing operation as one IR holds onto raw poultry as a second IR uses a knife to separate the parts, (c) Handling operation as an IR uses a mechanical gripper to unload a vine of tomatoes from a box, (d) Packaging and palletizing operation as a IR with several suction cups transfers a pallet of eggs from the processing belt into a box.

B. Hazardous and unfavourable environments; in many instances, the conditions at which food is manufactured can be considered hazardous or unfavourable, for example, handling heavy objects during loading and unloading tasks into machinery or packaging and palletising at end of processing line. Other hazardous processes can be found in meat processing facilities using dangerous tools within slaughterhouses or bakeries with raised platforms. In response to come of the hazards associated with slaughterhouses, Scott Technology in New Zealand established a lamb processing facility with a dozen robots forming an assembly line which can process up to 600 carcasses per hour, with one monitoring human worker [19]. Other processing facilities may require wet rooms, or certain temperature-controlled environments (e.g. walk-in freezers, roll-in ovens) which can become intolerable for employees. KUKA Robotics have developed and implemented IRs which can withstand and perform $100 \%$ efficiently and flexibly in temperatures down to $-30^{\circ} \mathrm{C}$. [36].

C. Simple and repetitive processes; many processes in large scale food production are simple and/or repetitive, examples include placing ingredients on a sandwich as it moves along a processing line or placing products into their packaging. Over time, these can become tedious and mundane to human employees, which in turn can affect the quality of processing and products if they become tired or bored. Allowing automation to perform such tasks will permit existing employees to be reutilised within higher level tasks. Automating such processes, may aid in eliminating labour fatigue and repetitive task injuries, which will improve employee safety, as well as limiting product faults and decreasing food waste. To automate the simple and highly repetitive process of pick and place, ABB Robotics launched the IRB 360 Flexipicker ${ }^{\circledR}$ which achieves up to 200 picks per minute once fitted with a gripper appropriate for the foodstuff handled. [1].

D. Highly variable production; many facilities are moving towards producing a large variety of products. During product changeovers, processing lines may be halted for extended periods of time as machinery is washed down, recipes are reviewed, and employees reassembled. The introduction of automatic machinery allowed more leeway for producers to provide a variety of products and quickly respond to market demands, however, variability was still limited, machines produced large amounts of waste and had no volument flexibility. [35]. Automating these processes and tasks allows for faster interchangeability between processes and products, thus adapting consistent production and quality. This requires highly flexible and reconfigurable systems that are able to maintain demand.

\subsection{IR Configurations within Food Manufacturing}

Generally, three IR configurations are found to be dominant in food processing operations due to their various applications and benefits; these are the delta (parallel robot, articulated robot and cartesian (Gantry robot. Table 1 displays their characteristics, associated advantages and disadvantages, and common applications $[17,26]$. These IR configurations have been applied in several processes. The first of these is material handling, which may involve sorting, transporting, weighing and loading of foodstuffs. The second is material processing, which covers the preparation of foodstuffs, for example; size reduction, separation and slaughtering. The third is assembly, in which IR are involved in foodstuff mixing, assembling or decoration of pre-prepared ingredients for food delivery. The fourth is packaging and palletising, including primary, secondary and tertiary packaging and palletising of finished food products. Packaging and palletising see the majority of IR used in the food industry, because the material handled is most likely to be structured, regular in shape, rigid and sealed, meaning it's less contaminable, for example, canned goods $[9,46]$. The last process inspection involves systems that check for quality and deformations, with rejected items being automatically removed. Some of these operations are illustrated in Figure 2. [5,8,9,36,44-46,48]. 
Table 1. Top 3 IR Configurations with Applications in Food Manufacturing [21,29].

\begin{tabular}{|c|c|c|c|}
\hline $\begin{array}{c}\text { Physical } \\
\text { Configuration }\end{array}$ & Articulated & $\begin{array}{c}\text { Delta } \\
\text { (Parallel) }\end{array}$ & Cartesian \\
\hline $\begin{array}{c}\text { Work } \\
\text { Envelope }\end{array}$ & Sphere & Hemi-Sphere & Rectangular \\
\hline Advantages & $\begin{array}{c}\text { High } \\
\text { Accuracy } \\
\text { High } \\
\text { Flexibility } \\
\text { Large Work } \\
\text { Volume } \\
\text { Speed } \\
\text { High } \\
\text { Payloads }\end{array}$ & $\begin{array}{c}\text { High Speed } \\
\text { High Accuracy } \\
\text { High } \\
\text { Flexibility } \\
\text { Low Weight }\end{array}$ & $\begin{array}{l}\text { High Payloads } \\
\text { Simple Control } \\
\text { High Rigidity } \\
\text { High Accuracy } \\
\text { Low Cost }\end{array}$ \\
\hline Disadvantages & $\begin{array}{c}\text { Large Size } \\
\text { Variable } \\
\text { Cost }\end{array}$ & $\begin{array}{l}\text { Complex } \\
\text { Algorithms } \\
\text { Restricted } \\
\text { Work } \\
\text { Envelope }\end{array}$ & $\begin{array}{c}\text { Difficult } \\
\text { Maintenance } \\
\text { Limited Work } \\
\text { Envelope } \\
\text { Limited } \\
\text { Flexibility }\end{array}$ \\
\hline Applications & $\begin{array}{l}\text { Assembly } \\
\text { Material } \\
\text { Handling } \\
\text { Packaging } \\
\text { Palletising } \\
\end{array}$ & $\begin{array}{c}\text { Material } \\
\text { Handling } \\
\text { Packaging } \\
\text { Palletising }\end{array}$ & $\begin{array}{l}\text { Material } \\
\text { Handling } \\
\text { Assembly } \\
\text { Palletising } \\
\text { Palletising }\end{array}$ \\
\hline
\end{tabular}

\section{CHALLENGES OF IRS IN FOOD MANUFACTURING}

Despite the above-mentioned applications of IR in food production, the rate of their uptake remain slow in comparison to other manufacturing industries. The fundamental challenges impacting their adoption in food manufacturing stems from four main areas, as highlighted below.

\subsection{Food Characteristics and Organoleptic Properties}

The greatest challenge deterring the uptake of IR in food manufacturing is the nature of the foodstuff itself. Foods are naturally fragile, non-rigid and irregularly shaped objects, which may be slippery or sticky. Improper handling and processing of foodstuffs can greatly affect their organoleptic properties, i.e. their taste, smell, colour or texture. Foodstuffs must be handled with care as slight pressures may cause deformities and bruising, affecting the quality of the ingredients and subsequently the products being processed. [10]. Table 2 displays examples of foodstuffs characteristics and the types of organoleptic damages that may occur in cases of improper handling. It is also important to note that such characteristics differ between the various states of foodstuffs during a cooking cycle. The need for special handling particularly prevalent in non-rigid and semi-rigid foodstuffs, which will most likely be subjected to textural and structural damages. [30]. The need for IR systems to recognise and respond to foodstuffs non-rigidity is stressed by Erzincanli and Sharp [14]. Because of these varying requirements, it is difficult to design a universal end-effector for the food industry, hence, the high number of bespoke end-effectors currently in use. Such requirements have inspired the development of several unique endeffectors, one example is based on the use of the Bernoulli principle to generate an airflow between a gripper and slippery slices of cucumber and tomatoes to be layered on a sandwich. This non-contact method allows the foodstuffs to maintain their physical properties and increases hygiene. [44]. Furthermore, IR may also be integrated with intelligent sensor technologies that allow the systems to react to these aspects in order to avoid deformation [42].

\subsection{Hygiene Requirements}

Optimum hygiene standards must be maintained in food processing facilities [6]. Unhygienic equipment or facilities may cause serious food safety issues. It is mandatory that all foods are handled and processed by equipment that are made from non-toxic, noncorrosive and easily washable materials; for example, stainlesssteel. Furthermore, they must be free of any crevices to avoid the build-up of food residue, which can cause microbial contamination. [9]. Many assumptions are often made about IR being unhygienic, however, a solution for this is described in Muller et al. [40], in which robots are coated with both permanent and detachable protective layer to ensure easy cleaning and protection against corrosion. Emerging food grade IRs are built for clean-in-place operations in which they can withstand wash downs with both soap and detergents for easier and faster cleaning [42]. The APRIL ${ }^{\mathrm{TM}}$ Robotic Chef designed by Olympus Automation Ltd. is an articulated IR that collects food-based materials from stations placed circularly around it, and mixes them to produce soups and sauces. Afterwards the robot automatically moves into a washing station in which it's end-of-arm tooling and the vessel used are washed down before moving onto the next batch. [59].

\subsection{Economic and Social Barriers}

Initial perception of IR was that they were expensive, rigid pieces of machinery that require complex set-up and highly skilled running procedures [56]. These assumptions greatly deter the rate at which IR are adopted in food processing, specifically within SMEs. Typically, in any food manufacturer, increasing production and meeting demands are the top priorities, which overtakes the time and resource required for IR implementation. Although modern technological advancements have introduced a wide variety of affordable IR that are easier to install and operate, many companies are tentative of investing in this technology due to their technophobia [53]. Another challenge robots face is the perceptions by wider society, and fears by individuals that they will be rendered redundant through uptake of IR. However, IRs cannot replace humans, rather, they are a mean of improving working environments and ensuring that sufficient amounts of food are produced to sustain the world's ever-increasing population and their demands.

\subsection{Shortages of Skilled Operators}

The food industry's "limited access to professional engineering and IT skills" greatly hinders the uptake of IR [9] and has been outlined as one of the major limitations in the adoption of advanced automation. The food producers ever-changing product range and production schedules allow very limited time and resources to employ third party consultants, thus there is a need to incorporate the knowledge regarding IRs applications and their benefits within food industry. SMEs especially often do not have sufficient knowledge or experience in this area and therefore require additional support from specialists [56].

Similarly, IR engineers lack the knowledge of foodstuff's natural characteristics, and the difficult factors involved in its handling and processing. [10]. There is a general perception that handling foodstuff or their production processes are too complicated for robots, however, according to Bennett Brumson of the Robotic Industries Association (RIA) "The more complex a process the more one should consider a robot" [8]. The introduction of collaborate robots, also known as cobots, will greatly change the dynamics of IR and human interaction in manufacturing. Integration of 3D vision, force sensors and highly technological IR-human interfaces such as augmented reality and smart glasses allow the utilization of both human experience and IR's versatility to produce high quality products. $[17,36]$. 
Table 2. Example of foodstuff characteristics and the effects of improper handling to their organoleptic properties.

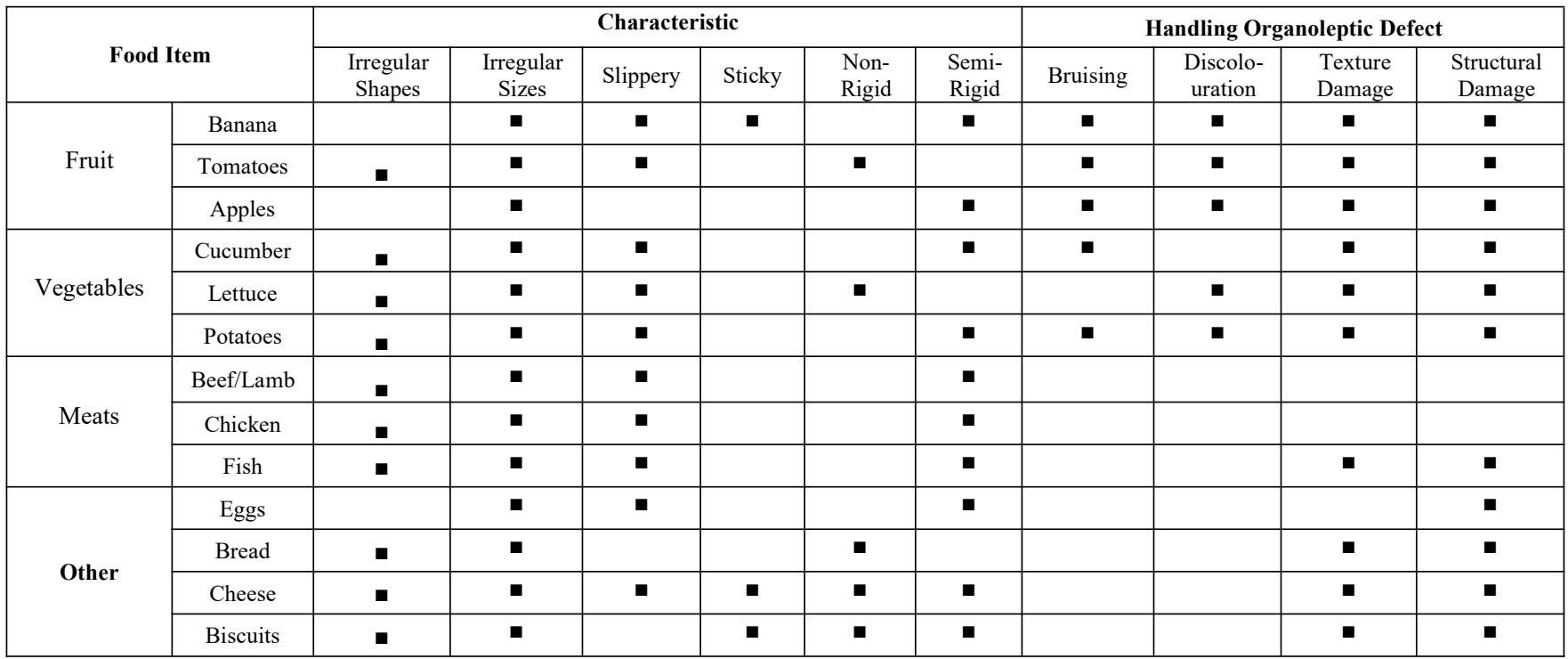

Table 3. General Benefits of using IR in Food Manufacturing.

\begin{tabular}{|c|c|c|}
\hline & IR Benefit & Further Outcomes \\
\hline 1 & $\begin{array}{l}\text { Reduce production } \\
\text { cost }\end{array}$ & $\begin{array}{l}\text { 1.1. Eliminate costs associated with employing, training and ensuring manual labour } \\
\text { 1.2. Reduce energy bills as no special lighting or thermal controls required } \\
\text { 1.3. } 24 / 7 \text { continuous production }\end{array}$ \\
\hline 2 & $\begin{array}{l}\text { Reduce material } \\
\text { waste }\end{array}$ & $\begin{array}{l}\text { 2.1. Efficient use of base materials, therefore less waste from scrap } \\
\text { 2.2. Seamless processing meaning less waste from rejects } \\
\text { 2.3. By reducing material and product reject waste, capital costs are reduced }\end{array}$ \\
\hline 3 & $\begin{array}{l}\text { Reduce capital } \\
\text { costs }\end{array}$ & $\begin{array}{l}\text { 3.1. No spending on direct labour } \\
\text { 3.2. "Lights-Out"' production }\end{array}$ \\
\hline 4 & Reduce floor space & $\begin{array}{l}\text { 4.1. Proper space utilization as robots can be mounted on walls, floors and ceilings; high } \\
\text { dexterity } \\
\text { 4.2. Work envelope can be confined and compact }\end{array}$ \\
\hline 5 & $\begin{array}{l}\text { Reduce production } \\
\text { time }\end{array}$ & $\begin{array}{l}\text { 5.1. Robot able to reach optimum speed } \\
\text { 5.2. No delays caused by fatigue, sick leaves or holidays } \\
\text { 5.3.Increased productivity }\end{array}$ \\
\hline 6 & $\begin{array}{l}\text { Improve product } \\
\text { quality and } \\
\text { uniformity }\end{array}$ & $\begin{array}{l}\text { 6.1. Errors caused by fatigue are eliminated } \\
\text { 6.2.Efficient process control } \\
\text { 6.3. High accuracy and seamless processing with high repeatability } \\
\text { 6.4. Sensors and inspection systems ensure top quality }\end{array}$ \\
\hline 7 & $\begin{array}{l}\text { Improve working } \\
\text { environment }\end{array}$ & $\begin{array}{l}\text { 7.1. Removes employees from hazardous, tedious and hostile tasks in unfavourable conditions } \\
\text { 7.2. Existing staff trained for higher level tasks, improves motivation } \\
\text { 7.3. Training staff to program and maintain the robots improves their skills } \\
\text { 7.4. Reducing risks allow for less stressful working environment }\end{array}$ \\
\hline 8 & $\begin{array}{l}\text { Increased } \\
\text { production rates }\end{array}$ & $\begin{array}{l}\text { 8.1. Able to perform } 24 / 7 \text { without breaks } \\
\text { 8.2. 'Lights-Out'" production } \\
\text { 8.3. Offline programming allows for production to continue without disruptions }\end{array}$ \\
\hline 9 & Increased flexibility & $\begin{array}{l}\text { 9.1. Quick reconfigurability and switching between processes } \\
\text { 9.2. Sensor integration allows for handling of different product varieties } \\
\text { 9.3.Fast interchangeability } \\
\text { 9.4. Easy re-scalability up or down } \\
\text { 9.5. Customisation, personalisation and wider varieties }\end{array}$ \\
\hline 10 & $\begin{array}{l}\text { Increased } \\
\text { Reconfigurability }\end{array}$ & $\begin{array}{l}\text { 10.1. Faster process changes; easily reprogramed } \\
\text { 10.2. Faster product changes } \\
\text { 10.3. Faster adaptability to demands } \\
\text { 10.4. Versatility allows for quick changes } \\
\text { 10.5. Faster response to market demand; increased competitiveness }\end{array}$ \\
\hline 11 & Increased Hygiene & $\begin{array}{l}\text { 11.1. Eliminates human contact with foodstuffs } \\
\text { 11.2. Decreased incidents of cross-contamination } \\
\text { 11.3. Better conformity to legislation } \\
\text { 11.4. Increased food safety }\end{array}$ \\
\hline 12 & $\begin{array}{l}\text { Increased safety } \\
\text { compliance }\end{array}$ & $\begin{array}{l}\text { 12.1. Able to work in hazardous and unfavourable environments } \\
\text { 12.2. Take over tedious, repetitive and mundane jobs } \\
\text { 12.3. Eliminates work related injuries; improved employee safety }\end{array}$ \\
\hline 13 & $\begin{array}{l}\text { Increase competitive } \\
\text { advantage }\end{array}$ & $\begin{array}{l}\text { 13.1. Instant supply chain responsiveness } \\
\text { 13.2. Increased product variability, allowing for customization and personalization }\end{array}$ \\
\hline 14 & Increased efficiency & $\begin{array}{l}\text { 14.1. Optimize processes, increasing speed of production } \\
\text { 14.2. Increase yield with accurate production }\end{array}$ \\
\hline
\end{tabular}




\section{BENEFITS OF IR IN FOOD MANUFACTURING}

It is argued that if these challenges are overcome, there are significant benefits offered by IR within food processing applications [1,2,28,29,40,47], a number of which have been summarised in table 3 . These include increased hygiene, safety flexibility, reconfigurability and speed, as well as ensure conformity to legislations. Most importantly, adopting IR in food processing will greatly facilitate the smooth transition into Industry 4.0 and allow for utilisation of IoT concepts which promises to provide food manufacturers with better traceability and trackability of all ingredients, processes and products, vastly improving food and consumer safety measures. The use of sensors and detection technologies will also enable advanced food labelling and decrease food waste. Furthermore, through supply chain integration, manufacturers can achieve faster market response and product launch. [50].

\section{FUTURE PROJECTIONS AND CONCLUSIONS}

In a report by Allied Market Research [45], it has been stated that by 2023 the global food robotics market will have a value of $£ 2,787$ million. Technological advancements will allow for more food handling end-effectors to be designed and used, especially for the handling of non-rigid foodstuffs. However, to ensure successful integration of IR, food manufacturers need to thoroughly analyse their food stuff and their automation options for proper utilisation and provision of maximum benefits [47].

As the demand by consumers for a higher variety of products continues to increase, the need for higher productivity and flexibility will continue to be a main concern. This is currently difficult with the shortage of labour across the food industry within many developed countries. This highlights the need for food manufacturers to adopt a higher level of technology to efficiently meet all challenges. IR, as a stepping stone into Industry 4.0, present the characteristics and properties suitable for such continuous advancements.

Finally, systematic approaches and methods for the planning and selection of the most appropriate IR for a specific food processing application to ensure the rapid uptake forms the future of this research.

\section{ACKNOWLEDGEMENTS}

This work was supported by the Engineering and Physical Sciences Research Council [grant number EP/K030957/1], under a research programme entitled the 'EPSRC Centre for Innovative Manufacturing in Food

\section{REFERENCES}

[1] ABB, ABB Robotics Product Specification IRB 360, (2018).

[2] ABB Group, 10 good reasons to invest in robots Robotics, 2009.

[3] BARA, When to not use Robots $\mid$ BARA, (n.d.).

[4] BDO, 2017 Food and Drink Report, A New Econ. Publ. (2017).

[5] BEIS, Digest of United Kingdom Energy Statistics, 2016.

[6] R. Bogue, The role of robots in the food industry: a review, Ind. Robot An Int. J. 36 (2009) 531-536.

[7] C. BRI, Campden BRI release results of food and drink innovation survey at Campden BRI, (2017).
[8] B. Brumson, Food Robotics Comes of Age, (2011).

[9] D.G. Caldwell, Robotics and Automation in the Food Industry, 2013.

[10] P.Y. Chua, T. Ilschner, D.G. Caldwell, Robotic manipulation of food products - A review, Ind. Robot An Int. J. 30 (2003) $345-354$.

[11] H. Colestock, Industrial Robotics: Selection, Design, and Maintenance, McGraw-Hill, USA, 2004.

[12] DEFRA, Food Statistics Pocketbook 2016, 2016.

[13] F. Erzincanli, J.M. Sharp, Meeting the need for robotic handling of food products, Food Control. 8 (1997) 185-190.

[14] F. Erzincanli, J.M. Sharp, A classification system for robotic food handling, Food Control. 8 (1997) 191-197.

[15] FDF, Reformulation, Food Drink Fed. (2017).

[16] P.J. Fellows, Food Processing Technology, Third, Woodhouse, Cambridge, 2009.

[17] J. Fryman, B. Matthias, Safety of Industrial Robots: From Conventional to Collaborative Applications, Robot. Proc. Robot. 2012; 7th Ger. Conf. (2012) 1-5.

[18] FSA, Guidance Notes for Food Business Operators on Food Safety, Traceability, Product Withdrawal and Recall, 2007.

[19] L. Garfield, JBS meat processing company will test Scott Technology robot butchers, Bus. Insid. (2016).

[20] M. Groover, M. Weiss, R. Nagel, N. Odrey, Industrial Robotics; Technology, Programming and Applications, McGraw-Hill Book Company, 1986.

[21] M.P. Groover, Automation, Production Systems, and Computer-Integrated Manufacturing, Fourth Edi, Pearson Education Ltd, Essex, 2016.

[22] HSE, Food and drink manufacture, Heal. Saf. Exec. (n.d.).

[23] HSE, Work-related Musculoskeletal Disorder (WRMSDs) Statistics, Great Britain 2016, 2016.

[24] IFR, Executive Summary World Robotics 2017 Industrial Robots, World Robot. Rep. (2017) 15-24.

[25] IGD, What are shoppers prioritising when it comes to diet?, IGD Shopp. Vista. (2017) 2016-2018.

[26] IGD, Generation Change: Maximising Growth from PostMillennial Shoppers, IGD Shopp. Vista. (2017) 1-7.

[27] ISO, ISO 8373:2012(en), Robots and robotic devices Vocabulary, (n.d.).

[28] UFoST, Food Traceability, 2012.

[29] R.N. Jazar, Theory of Applied Robotics; Kinematics, Dynamics, and Control, 1st ed., Springer US, 2007.

[30] L. Jennergren, Flexible Assembly of Ready-to-eat Meals, Orebro University, 2004.

[31] E. Kafrissen, M. Stephans, Industrial Robots and Roboticas, Reston Publishing Company, Inc., Virginia, 1984.

[32] A. Kamenetz, The Four Things People Can Still Do Better Than Computers, (2013).

[33] J. Kearney, Food consumption trends and drivers, Philos. Trans. R. Soc. B Biol. Sci. 365 (2010) 2793-2807.

[34] L. Kodituwakku, I. Nobel, V. Apostolidis, Sustainable Growth in the Food and Drink Manufacturing Industry, Grant Thornt. Rep. Comm. by Food Drink. Fed. (2013). 
[35] Y. Koren, M. Shpitalni, Design of reconfigurable manufacturing systems, J. Manuf. Syst. 29 (2010) 130-141.

[36] KUKA, KUKA robots for the food industry, 2013.

[37] I. Maly, D. Sedlacek, P. Leitao, Augmented Reality Experiments with Industrial Robot in Industry 4 . 0 Environment, Ind. Informatics. 14 (2016) 176-181.

[38] J.J. McCluskey, Changing consumer preferences, in: Washington State University (Ed.), The 60th Annual Conference of Australian Agricultural and Resource Economics Society, Canberra, Australia, 2016.

[39] A. Melanson, What Industry 4.0 Means for Manufacturers, Aethon. (2015).

[40] M. Mueller, B. Kuhlenkoetter, R. Nassmacher, Robots in Food Industry Challenges and Chances, ISR/Robotik 2014. (2014) 232-238.

[41] A. Murray, CEOs: The New Industrial Revolution Is Coming, Fortune.com. (2016).

[42] G.A. Nayik, Robotics and Food Technology: A Mini Review, J. Nutr. Food Sci. 5 (2015).

[43] R. Pendrous, Marshmallow maker Boomf installs robotic ultrasonic cutter, (2016).

[44] A. Pettersson, S. Davis, J.O. Gray, T.J. Dodd, T. Ohlsson, Design of a magnetorheological robot gripper for handling of delicate food products with varying shapes, J. Food Eng. 98 (2010) 332-338.

[45] A. Prasannan, Food Robotics Market Overview, Allied Mark. Res. (2017).

[46] PwC Global, What we mean by Industry 4.0, (n.d.).

[47] J. Ridler, Christmas will "grind to halt" without EU workers, Foodmanufacture.co.uk. (2017).
[48] J. Schweder, Turning Out the Lights on the Factory Floor, Autom. World. (2017).

[49] SEMLEP, Food \& Drink Summary Report 2015, 2015. Industry 4.0, (2016).

[50] UK-RAS Network, Manufacturing Robotics: The Next Robotic

[51] E. Smethurst, Food manufacturers should prepare for Industrial Revolution, Birmingham, 2016.

[52] P.J. Wallin, Advanced Robotics in the Food Industry, Ind. Robot An Int. J. 20 (1993) 12-13.

[53] P.J. Wallin, Review of the use of robotics and opportunities i1995) 9-11.

[54] Pn the food and drinks industry, Ind. Robot An Int. J. 22 (.J. Wallin, Robotics in the Food Industry: An Update, Trends Food Sci. Technol. 8 (1997) 193-198.

[55] A. Wheeler, Lights-Out Manufacturing: Future Fantasy or Good Business, (2015).

[56] M. Wilson, Developments in robot applications for food manufacturing, Ind. Robot An Int. J. 37 (2010) 498-502.

[57] D. Wolfe, Superfoods : the food and medicine of the future, North Atlantic Books, 2009.

[58] WRAP, Estimates of Food Surplus and Waste Arisings in the UK, 2017.

[59] APRIL Robotic Food Processing, (n.d.) 